\title{
EDITORIAL
}

\section{Acerca de la prevención en Salud Mental}

Aunque no hay consenso, sí parece razonable aceptar que las condiciones cambiantes de la sociedad actual explican cierto aumento de la patología psíquica.

En todo caso la tasa de patología mental en la población general se suele situar alrededor del $15 \%$ y se duplica, alcanzando más del $30 \%$, entre los pacientes que acuden a los Centros de Atención Primaria.

En nuestro país, los Programas de Prevención en Salud Mental vienen arrastrando un estado de deficiente implantación y de permanente crisis, hasta el punto de que no se ha superado el carácter experimental de la mayoría de ellos. Se realizan diseños, con frecuencia, con la intención de conseguir un alto grado de generalización y continuidad, pero rara vez alcanzan sus objetivos. Este estado de la cuestión es similar al resto de los países europeos.

El panorama que presenta la prevención en salud mental es de escasez de programas que se ejecutan, y de ellos, unos terminan por decaer y otros desaparecen. Por tanto, la cuarta revolución en salud mental, como se conoce a la prevención primaria, ha venido subsistiendo en crisis.

Tampoco se destinan recursos económicos y sociales que favorezcan la reducción de la génesis de los trastornos mentales, aunque se conoce que determinadas condiciones de vida aumentan la vulnerabilidad de las personas y que, sobre esas condiciones, resulta esencial la participación comunitaria.

En España, si exceptuamos la prevención en drogodependencias, apenas se realiza prevención primaria en salud mental. La prevención actualmente consiste en unos cuantos programas o intervenciones preventivas más o menos planificadas, efectuadas con gran esfuerzo de los profesionales, que en la mayoría de los casos son iniciativas basadas en la voluntad o en la capacidad de empuje de una o un pequeño grupo de personas, y generalmente con limitados resultados prácticos.

Por otra parte, el desarrollo de los Programas de Prevención en Salud Mental ha estado contaminado por algunos componentes políticos e ideológicos que han debilitado su aspecto científico. Incluso se ha reprochado que sus costes económicos han obligado a reducir otras partidas presupuestarias dedicadas a la asistencia.

En general, la crisis de la prevención se atribuye, con razón, a la falta de voluntad política para desarrollar los programas, lo que contrasta con algunas declaraciones de los responsables políticos a los medios de comunicación sobre la importancia que tiene y se le otorga a la prevención.

Pero la falta de implicación de la Administración Pública deber ser, sin embargo, matizada porque también se vislumbran resistencias en la sociedad y en los profesionales para la puesta en marcha de programas de prevención.

La ejecución de los programas de prevención debe pasar necesariamente por la mediación de actores sociales, y éstos parecen influidos por los estereotipos del imaginario social. De forma que incluso el retraimiento o la inhibición política puede encontrar aliado en las características de la respuesta social. La crisis de la prevención puede, por tanto, ser 
explicada de una forma bastante coherente desde la perspectiva de las dificultades que la propia estructura sociopolítica contiene y genera.

También hay que plantearse la posibilidad de la desmotivación de los profesionales por la prevención. Apenas pueden cuestionarse siquiera la eventual colaboración en programas de prevención cuando están sobrecargados por la demanda. Aunque quizá no todos los profesionales hayan contemplado su práctica en la comunidad como inserta en una estructura social cuya función es la de agente de cambio y de transformación.

Tal vez también ha cundido el desánimo sobre la prevención porque, a pesar de la cantidad de publicaciones sobre esta materia, los resultados obtenidos hasta ahora han sido poco constrastables o inconsistentes y no se dispone de mucha evidencia para afirmar que sea efectiva por la falta de fundamentos teóricos. Pero esto último, ha sido contestado, en ocasiones desde una perspectiva empírica diciendo que lo único que tiene valor es la experiencia acumulada en el trabajo, lo que equivale a construir una inútil prevención sin evaluación.

Sin embargo, sería conveniente que se le concediera a la prevención en salud mental cierta relevancia científica y social porque trabajar en prevención no supone únicamente aplicar modelos predefinidos con efectos predecibles, sino participar en un proyecto que forme parte de un programa de investigación amplio, pluridisciplinar y transnacional.

La prevención en salud mental, por perspectiva comunitaria y por principio, invita a toda la comunidad a reflexionar de forma crítica sobre su propia postura ante conceptos, actitudes, valores y normas, sin olvidar la existencia de los cambios permanentes que emanan de los contextos sociales y culturales.

La prevención no es ni puede ser una técnica ni una metodología cerrada, definitiva o acabada. Más bien se caracteriza por ser una disciplina en constante evolución que rechaza los fundamentalismos y que adopta la forma de programa de investigación. Lo que conduce a que surjan bastantes preguntas que precisan aportaciones teóricas, metodológicas y de evaluación. Por eso no hay ni puede haber manuales de instrucciones ni fórmulas mágicas. A pesar de los problemas teóricos y prácticos de la prevención en salud mental, de su complejidad, de la ausencia de criterios que guíen las intervenciones y de que las expectativas que originen los programas de prevención no puedan ser todavía demasiado elevadas porque actualmente la prevención continúa siendo un bien con cierta dosis de utopía, cabría esperar un futuro moderadamente prometedor porque cada día es posible identificar más factores de riesgo, de resiliencia y de protección. Y aunque todavía no se disponga de la sabiduría adecuada para llevar a cabo programas de prevención magistrales, no justifica que no se realicen intervenciones preventivas con los conocimientos que se poseen.

La prevención es, hoy en día, además de una necesidad, un desafío para la ciencia y la sociedad.

El presente y el futuro de la prevención primaria en salud mental pasa por recuperar la perspectiva comunitaria con su complejidad e incertidumbres, por reconocer la importancia de la ecología, porque el individuo y la comunidad se hallan insertos en un 
EDITORIAL

sistema ecológico concreto, y por forzar una nueva definición de elementos conceptuales que den cabida a modelos teóricos o conceptos transvasados de otras disciplinas y que posibiliten la participación de distintos colectivos sociales, de asociaciones y profesionales que desarrollan su trabajo en el tejido social.

Sin duda, ha llegado el momento de ir formalizando Programas de Prevención en Salud Mental más completos y definidos. Para ello es ineludible su inclusión como un programa más en los Centros de Şalud Mental, la implicación y el apoyo de la Administración Pública en orden a los ajustes socioeconómicos en la planificación, el establecimiento de vías que posibiliten la participación comunitaria y la colaboración de diversos campos científicos, porque la prevención es intrínsecamente interdisciplinar. De lo contrario, únicamente florecerán discursos que giren entre el voluntarismo y las intervenciones descontextualizadas.

Fernando Mansilla 